\title{
Structural, photophysical, and photobiological studies on BODIPY-anthracene dyads
}

\author{
Susan Callaghan, ${ }^{[a]}$ Benedikte E. Vindstad, ${ }^{[b]}$ Keith J. Flanagan, ${ }^{[a]}$ Thor B. Melø, ${ }^{[b]}$ Mikael Lindgren, ${ }^{*[b]}$ \\ Kristin Grenstad, ${ }^{[b]}$ Odrun A. Gederaas, ${ }^{* b]}$ and Mathias O. Senge ${ }^{*[a]}$
}
[a] S. Callaghan, Dr. K. J. Flanagan, Prof. Dr. M. O. Senge
Medicinal Chemistry,
Trinity Translational Medicine Institute, Trinity Centre for Health Sciences,
Trinity College Dublin, The University of Dublin,
St. James's Hospital,
Dublin 8 (Ireland)
E-mail: sengem@tcd.ie; twitter: @mathiassenge
[b] B. E. Vindstad, Prof. T. B. Melø, Prof. M. Lindgren, K. Grenstad, Prof. O. A. Gederaas Department of Physics
Norwegian University of Science and Technology,
N-7491 Trondheim (Norway)
Supporting information for this article is given via a link at the end of the document

Callaghan, S.; Vindstad, B. E.; Flanagan,

K. J.; Melø, T. B.; Lindgren, M.; Grenstad,

K.; Gederaas, O. A.; Senge, M. O. (2021):

Structural, Photophysical, and

Photobiological Studies on BODIPY-

Anthracene Dyads. ChemPhotoChem 5,

$131-141$

https://doi.org/10.1002/cptc.202000191

\begin{abstract}
We report the structural, photophysical, and photobiological properties of a promising BODIPY-anthracene dyad (BAD) that was previously shown to i nduce a therapeutic effect against MDA-MB-468 cells. The BODIPY was synthesized and its crystal structure was elucidated. We further investigate the potential of this molecule as a versatile photosensitizer for photodynamic therapy against AY27 and F98 cancer cell models. Both necrosis and apoptosis were found to play a role in cell death and G1 phase arrestation was observed following PDT. From time-resolved spectroscopic analysis of absorbance and luminescence, it was found that the singlet oxygen quantum yield of the most promising BODIPYanthracene dyad is high $(>70 \%)$ and originates from a triplet state. Interestingly, despite the efficient PDT effect, long-lived triplet states or singlet oxygen formation were not observed when water (or $\mathrm{D}_{2} \mathrm{O}$ ) was used as the solvent but were readily observed in solvents such as $\mathrm{MeOH}$ and $\mathrm{EtOH}$.
\end{abstract}

\section{Introduction}

Photosensitizers interact with light and molecular oxygen to produce singlet oxygen $\left({ }^{1} \mathrm{O}_{2}\right)$. This so-called photodynamic effect has found medical application against malignant diseases and offers potential for antimicrobial treatments. ${ }^{1}$ Additionally, triplet excited state chromophores are employed as photocatalysts, ${ }^{2}$ OLEDs, ${ }^{3}$ and photon up-conversion agents. ${ }^{4}$ BODIPYs (borondipyrromethenes) are a class of photosensitizes that have been employed as photodynamic therapy agents because their photophysical properties can be modulated by chemical modification. ${ }^{5}$ To populate the triplet state, halogenation is often used to increase intersystem crossing by enhancing spin-orbit coupling (Fig. 1, compound 1). ${ }^{6}$ Another strategy employed when there are donor and acceptor units in the structure is photoinduced electron transfer. This leads to charge-separated states, which can undergo radical pair intersystem crossing (RPISC) or spin-orbit charge transfer intersystem crossing (SOCTISC) to form triplet states (Fig. 2). ${ }^{7}$

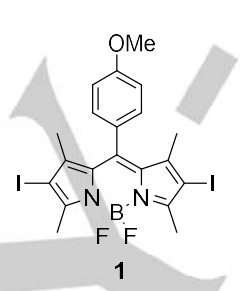

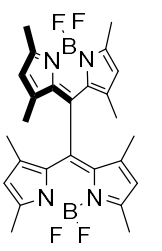

2

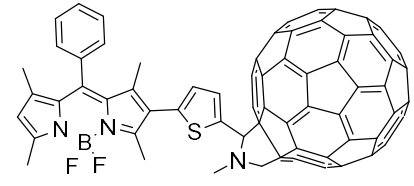

3
Figure 1: Examples of ${ }^{1} \mathrm{O}_{2}$-generating BODIPY-based molecules.

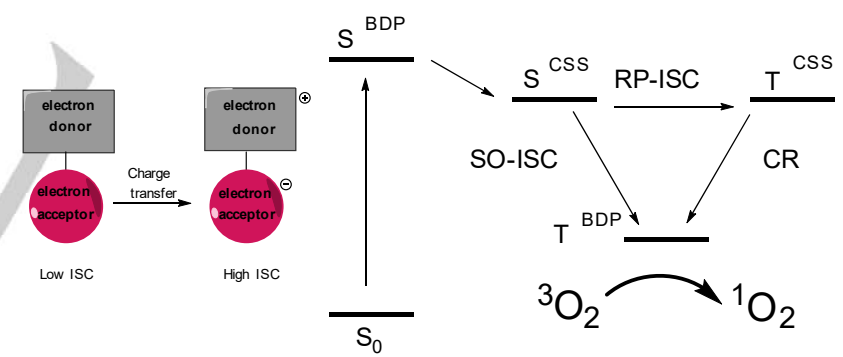

Figure 2: Schematic and Jablonski representation of ISC enhancement mediated by charge transfer.

Examples of these donor-acceptor systems include the dimer compound $2^{8}$ and the $\mathrm{C}_{60}$ conjugated BODIPY, compound $3 .^{9}$ Similar reactions take place with perylene dicarboxamides ${ }^{10}$ together with fullerene. ${ }^{11}$ Additionally, we reported a family of BODIPY-anthracene, -pyrene, and -perylene dyads that produce triplet states generated by photoinduced electron transfer. In 2019, Wang et al. confirmed that spin-orbit charge transfer induced intersystem crossing in these molecules. ${ }^{12}$ We also demonstrated that they are influenced by environmental polarity. In polar media, the charge-separated state is stabilized and triplet-state formation is enhanced. ${ }^{13}$ We investigated the in vitro toxicity of these BODIPY-anthracene and -pyrene dyads by chemically modifying to contain a zwitterionic fragment. We demonstrated that they induce cytotoxicity in human breast cancer cells (MDA-MB-468) at micromolar concentrations following light irradiation. BAD-3 
(Scheme 1) showed significant photocytotoxicity $(15 \%$ cell viability) at a concentration of $5 \times 10^{-7} \mathrm{M}$, with minimal toxicity $(89 \%$ cell viability) in the absence of light. ${ }^{14}$ Herein, we further investigate BAD-3 by elucidating its structure as well as its photophysical and photobiological properties.

\section{Results and Discussion}

\section{Structural Properties of BADs}

BADs (BODIPY-anthracene dyads) 1-3 were synthesized and characterized in accordance with our previous reports. This was achieved using a one-pot condensation and boron insertion reactions to yield the BODIPY, followed by fluorine substitution with $\mathrm{N}, \mathrm{N}$-dimethylaminopropyne-1 units and quaternization of the dimethylamino group with 1,3-propanesultone. The water-soluble zwitterionic BODIPYs (Scheme 1) precipitated from the non-polar solvent. ${ }^{13 a},{ }^{14} \mathrm{We}$ also obtained the first crystal structure of a watersoluble BAD (Scheme 1). To the best of our knowledge, the only other crystal structure of a zwitterionic BODIPY was reported by Sekhar et al. ${ }^{15}$ Interestingly, both hexane and water molecules are included in the unit cell, which confirms the hydrophobic and hydrophilic ends of the compound.

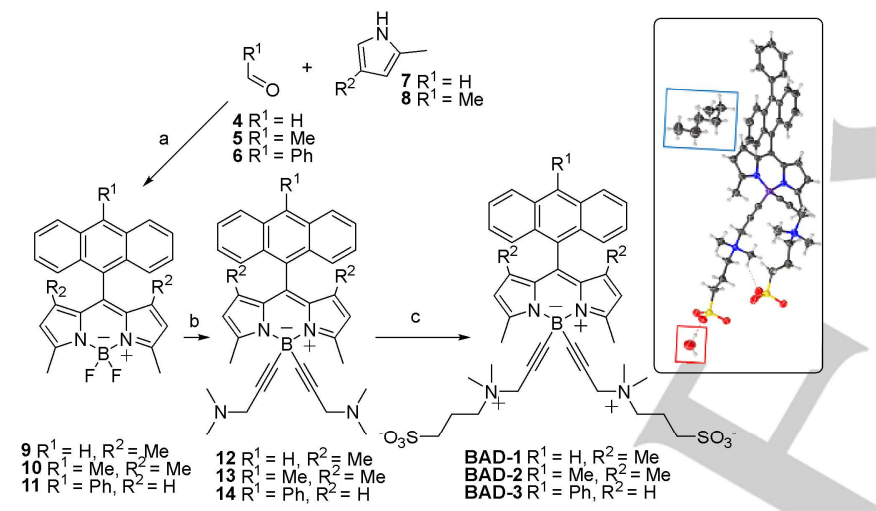

Scheme 1: General synthesis of water-soluble dyads. a) 1. TFA (cat.), DCM, rt, 16 h. 2 . DDQ (1 eq.), rt, 20 min. 3. DIPEA (10 eq.), $\mathrm{BF}_{3} \cdot \mathrm{Et}_{2} \mathrm{O}(10 \mathrm{eq}$ ), rt, $1.5 \mathrm{~h}$. b) 1. 3-Dimethylamino-1-propyne (4.5 eq.), THF, rt, $30 \mathrm{~min}$. 2. $n$-BuLi (4 eq.), $\mathrm{THF}, \mathrm{rt}, 2 \mathrm{~h}$; c) 1,3-propanesultone (6 eq.), EtOAc, $80^{\circ} \mathrm{C}, 2 \mathrm{~h}$. Inset: Molecular structure of BAD-3 showing the polar (red: water) and nonpolar (blue: hexane) solvents within the unit cell.

\section{Cell Viability}

In vitro toxicity was studied using MTT assays in both the AY27 rat bladder cancer and the F98 rat glioma cancer cell lines. ${ }^{16,17}$ Firstly, we found that the control group, without active photosensitizer, did not undergo significant cell death up to $240 \mathrm{~s}$ of light treatment in both cell lines, however, the F98 cell line appears to be more sensitive to light. For the AY27 cell line, BAD3 gave the strongest therapeutic response of the three BADs tested. After 1 min of treatment, we found that only $40 \%$ of cells survived while after 120 s less than $5 \%$ cell viability was observed. In contrast, over the period of the experiment (240 s), the cell viability of the cells treated with BAD-1 did not drop below $70 \%$ and BAD-2 required more than $120 \mathrm{~s}$ for less than $5 \%$ survival to occur. Therefore, BAD-3 was identified as the most potent photosensitizer against the AY27 cell line (Fig. 3). We then tested BAD-3 against the F98 rat glioma cancer cell line and obtained similar results, after $20 \mathrm{~s}$ of irradiation cell viability was $19 \%$ and after $120 \mathrm{~s}$, less than $5 \%$ cell viability was observed. These findings agree with our previous study. ${ }^{14}$ Thus, BAD-3 was chosen for further study.

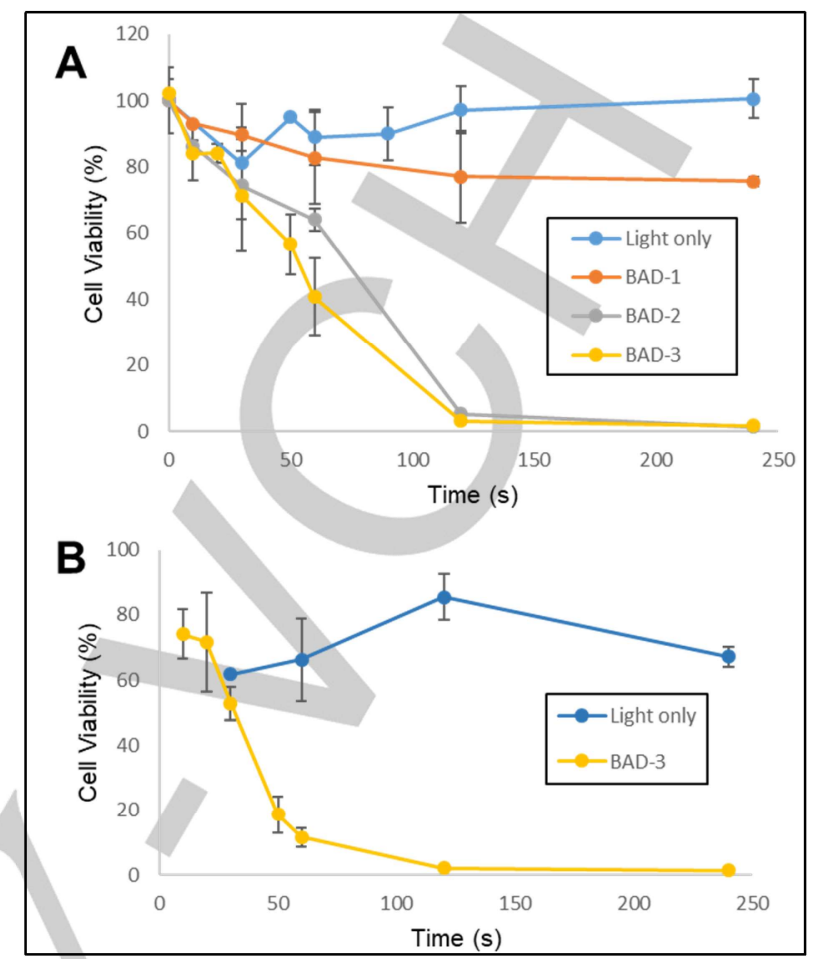

Figure 3: Cell survival curves of (A) AY27 and (B) F98 cells treated with $10 \mu \mathrm{M}$ of BADs 1-3. Viable cells were detected after varying exposure to light $(0-240$ $\mathrm{s}, 435 \mathrm{~nm}, 12.9 \mathrm{~mW} / \mathrm{cm}^{2}$ ). Control cells (light only) were exposed to light but not incubated with an active photosensitizer. The standard deviation of the values is indicated by the black bars.

We then continued with an investigation into the effect of photodynamic therapy on the AY27 cell population. Fig. 4a shows the number of cells harvested and counted, after treatment, using an automated cell counter from each experimental group. First, the control culture grew to $3.1 \times 10^{6}$ cells over the course of the experiment, which is six times larger than the seeded population. The illumination only groups, $30 \mathrm{~s}$ and $120 \mathrm{~s}$, had populations of $3.3 \times 10^{6}$ and $2.5 \times 10^{6}$ cells, respectively. These populations were similar to the controls with the 120 s group having a slightly lower population, indicating that $120 \mathrm{~s}$ of light treatment induces only minor toxicity. The BAD-3 only group presented a population of $2.4 \times 10^{6}$ cells, a reduction of $24 \%$ compared to the control group. This may indicate dark toxicity at a BAD-3 concentration of $10 \mu \mathrm{M}$. Finally, the groups treated with both BAD-3 and light (30 s or 120 s) showed a significant reduction in population size. The BAD-3 and $30 \mathrm{~s}$ light and BAD-3 and $120 \mathrm{~s}$ of light groups had final populations of $1.8 \times 10^{6}$ and $0.049 \times 10^{6}$ cells, a percentage reduction of $42 \%$ and $97.3 \%$, respectively, when compared to the control group. Thus, it can be concluded that the longer light treatment $(120 \mathrm{~s})$ is necessary to induce a strong cell death response.

\section{Mode of Cell Death}

To investigate the mode of cell death, cells from each experimental group were harvested and analyzed using flow cytometry. Scatter plots were formulated from the data, two of which are shown in Figure 4c and 4d. Each point represents one cell. Thus, the cells are sorted by the amount of annexin $V$ 
fluorescence detected along the $x$-axis, and propidium iodide $(\mathrm{PI})$ fluorescence along the $y$-axis. From the distributions of scores $(x, y)$, the population of each group was identified: i) viable, ii) dead by apoptosis, iii) dead by necrosis, and finally iv) late necrosis (Please refer to the SI for more details).

In Figure $4 \mathrm{~b}$, the resulting mean percentages of viable and dead cells in the harvested cell populations are presented. The fractions of early and late necrosis are combined in this plot. Five of the six groups show only very small variations, including the first treatment group, which received $30 \mathrm{~s}$ of light. All the experimental groups except the BAD-3 $(10 \mu \mathrm{M})$ with $120 \mathrm{~s}$ light group showed percentages of viable cells between $80 \%$ and $90 \%$, with necrosis being the major mode of cell death in these cases. Interestingly, for the BAD-3 and $30 \mathrm{~s}$ light group a large proportion of the cells were viable $(80 \%)$, this may indicate that this treatment prevents proliferation instead of directly inducing necrosis and/or apoptosis. In contrast, the second treatment group, which received illumination for $120 \mathrm{~s}$ and BAD-3 $(10 \mu \mathrm{M})$, has only $7.7 \%$ viable cells. Nearly $40 \%$ of the cells died by apoptosis and just under $60 \%$ died by necrosis. These results again suggest that a longer illumination time is necessary. Moreover, the observation of both necrosis and apoptosis is interesting as it may indicate the involvement of the immune system in addition to the classic apoptosis pathways. ${ }^{18}$ Additionally, G1 phase arrestation was observed following PDT (Fig. SI9).

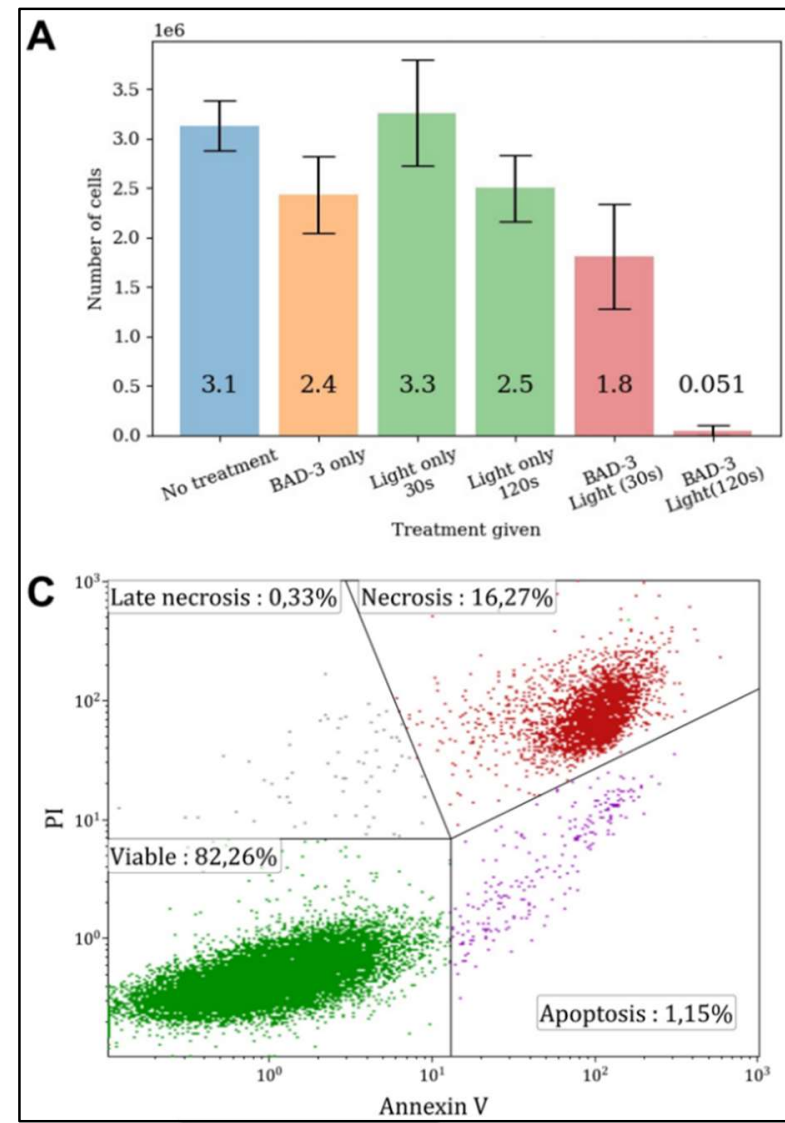

\section{Cell Morphology and BAD Localization}

AY27 cells from the experimental groups were visualized using microscopy. Some representative images are shown in Fig. SI10 and they largely confirmed the findings from the flow cytometer results. AY27 cells from the experimental groups were also visualized using fluorescence microscopy, as shown in Fig. 5. Low fluorescence was observed for cells that were treated with BAD-3 $(10 \mu \mathrm{M})$ but not light. In contrast, cells treated with BAD-3 $(10 \mu \mathrm{M})$ and $120 \mathrm{~s}$ of light showed increased fluorescence. The fluorescence signal from BAD-3 can clearly be seen originating from inside the cell membrane.

Figure 6 displays representative confocal fluorescence microscopy images of AY27 cells incubated with BAD-3 $(10 \mu \mathrm{M})$ and co-stained with Draq5 (DNA stain), LysoTracker Blue (lysosome stain) and CellMask Red (membrane stain). Firstly, these images confirm that BAD-3 crossed the cell membrane. Figure 6 A-C show AY27 cells incubated with Draq5 and BAD-3. A colocalization value of $4 \%$ was calculated, indicating poor nuclear localization. However, an average co-localization value of $22 \%$ was obtained for BAD-3 and the lysosomal stain in AY27 cells incubated with BAD-3 and co-stained with LysoTracker Blue and CellMask Red (Fig. 6 D-G), which indicates moderate lysosomal localization. ${ }^{19}$

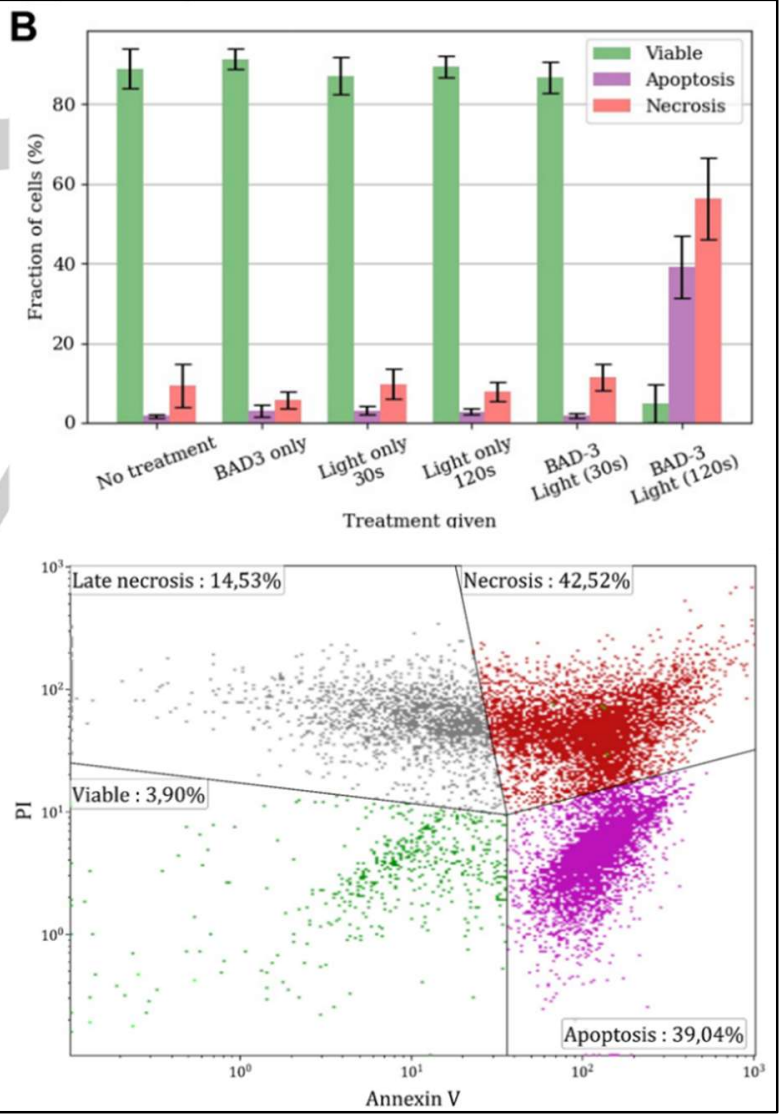

Figure 4: (A) Number of AY27 cells counted four days after seeding in each treatment group (no treatment, only BAD-3 (10 $\mu$ M), light only 30 s, light only $120 \mathrm{~s}$ BAD-3 $(10 \mu \mathrm{M})+$ light $30 \mathrm{~s}$, and BAD-3 $(10 \mu \mathrm{M})+$ light $120 \mathrm{~s})$ using blue light $\left(435 \mathrm{~nm}, 12.9 \mathrm{~mW} / \mathrm{cm}^{2}\right)$. The mean values from each group are presented, with the standard deviation within the group indicated by the black bars. (B) The mean percentage of viable, apoptotic and necrotic AY27 cells for experimental groups (no treatment, only BAD-3 $(10 \mu \mathrm{M})$, light only $30 \mathrm{~s}$, light only $120 \mathrm{~s}$, BAD-3 $(10 \mu \mathrm{M})+$ light $30 \mathrm{~s}$, and BAD-3 $(10 \mu \mathrm{M})+$ light $120 \mathrm{~s})$. Standard deviation is indicated by the black bars. (C) Scatter plots showing annexin $V$ and PI fluorescence of cells from no treatment group (left) and BAD-3 (10 $\mu M)+$ light $120 \mathrm{~s}$ (435 nm, 12.9 $\mathrm{mW} / \mathrm{cm}^{2}$, right) 

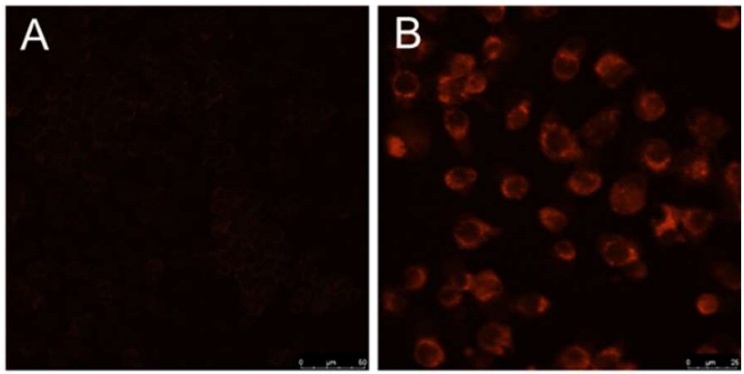

Figure 5: Fluorescence microscopy images of cells treated with BAD-3 (10 $\mu \mathrm{M})$ only $(A)$ and incubated with BAD-3 $(10 \mu \mathrm{M})$ and treated with $120 \mathrm{~s}$ of light $(B)$. Scale bar is $60 \mu \mathrm{m}$.
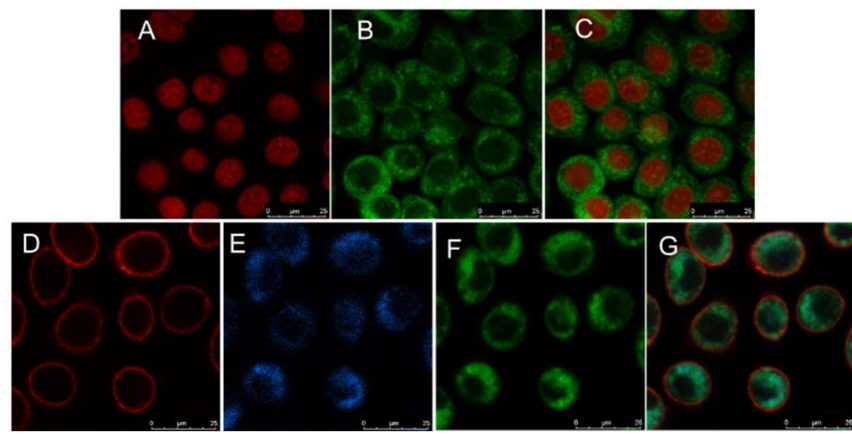

Figure 6: Confocal fluorescence microscopy images of AY27 cells co-stained with BAD-3 $(10 \mu \mathrm{M})$ and either Draq5 $(20 \mu \mathrm{M})$ or LysoTracker Blue $(75 \mathrm{nM})$ and CellMask Red (1 nM). Images A-C show colocalization of BAD-3 and Draq5, where $A, B$, and $C$ indicate the Draq5 channel $(680-722 \mathrm{~nm})$, BAD-3 channel $(519-545 \mathrm{~nm})$, and the colocalization of BAD-3 and Draq5 channel, respectively. Images D-G show colocalization of BAD-3, LysoTracker Blue and CellMask Red, where D, E, F, and G indicate the CellMask Red channel $(670-712 \mathrm{~nm})$, LysoTracker Blue channel (409-471 nm), BAD-3 channel, and the colocalization of all three channels, respectively. The colored images have been modified for clarity by adding brightness. The scale bar is $25 \mu \mathrm{m}$.

\section{Photophysical studies}

The generation of triplet excited states via photoinduced electron transfer in BODIPY-anthracene dyads has been outlined in detail by Filatov et. al. ${ }^{13 a}$ Generally, a charge-separated state (CSS, with an anion localized on the BODIPY core and a cation on the anthracene unit) is formed very fast (1-5 ps range) and may decay to a triplet state. The triplet state can in turn produce singlet oxygen from oxygen dissolved in the solvent and possible photorearrangement products may be formed via [4+2] cycloaddition reactions between singlet oxygen and the aromatic moiety. ${ }^{13 a, 20}$

Herein, the focus is on the spectroscopy of the triplet states and generation of singlet oxygen, although the absorption and emission spectra of BAD-3 in acetonitrile (ACN) are shown in Fig. 7 to introduce the complexity of the BAD systems. The absorption of BAD-3 shows the characteristic bands due to the BODIPY moiety around $450-500 \mathrm{~nm}$ and the typical absorption of the anthracene unit below $400 \mathrm{~nm}$. The emission spectrum (solid line) is composed of two parts, a sharp feature around $525 \mathrm{~nm}$ and a broad featureless band centered at $700 \mathrm{~nm}$, color coded blue and red, respectively, in Figure 7. Exposing the same sample to sunlight for a few minutes does not change the absorption spectrum considerably but there is a strong increase in the emission around $525 \mathrm{~nm}$. The quantum efficiency (QE, see Fig. SI11:A) of the 'pristine' BAD-3 was here determined to be only $0.49 \%$ with approximately a quarter of that belonging to the sharper $525 \mathrm{~nm}$ feature (the blue part of the emission in Fig. 7). Following photo-bleaching, the overall fluorescence QE increased to approximately $2 \%$. As the sample is undergoing these photochemical changes during the measurement process the determined numbers here should be considered approximate and 'upper limits'. For similar reasons, it is difficult to make any quantitative steady-state characterizations of the BADs.

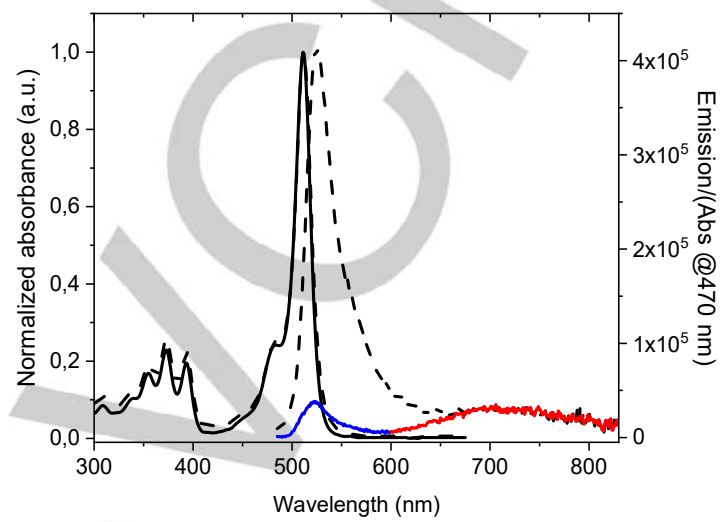

Figure 7: Absorption and emission of $10 \mu \mathrm{M}$ BAD-3 in ACN. The filled lines indicate pristine BAD-3, the dashed lines are for BAD-3 that has undergone exposure to sunlight for 5 minutes. The absorption spectra are normalized to 1 , whereas the emission spectra have been normalized to the absorbance at the excitation wavelength, here $470 \mathrm{~nm}$. See text for further details.

Attempted time-correlated single photon counting (TC-SPC) yielded a life-time of nearly $7 \mathrm{~ns}$ for the photo-produced species at $525 \mathrm{~nm}$ (Fig. SI11B) whereas the life-time for the $525 \mathrm{~nm}$ band of the pristine sample was slightly faster but comprised of several components (see Fig. SI11B). Conclusively, these emission features can be assigned to fluorescence. The broad feature at $700 \mathrm{~nm}$ is typical of charge transfer complex, ${ }^{21}$ but it was difficult to characterize its time-response, due to the efficient photodecomposition in solution. Instead the combined time-gated and low temperature approach was employed, giving the emission spectra as shown in Fig. 8. By changing the gate-delay between the laser fire and the measurement, the fluorescence was first identified at $525 \mathrm{~nm}$ together with some scattered laser light (475 $\mathrm{nm})$. Upon delaying the gate, the relative yield of the fluorescence at $525 \mathrm{~nm}$ decreases and the broad $700 \mathrm{~nm}$ feature increased and became dominant.

To obtain quantitative values of the decay of this emission, the delay was set to approximately $80 \mathrm{~ns}$ to avoid fluorescence and laser excitation. Then, the $700 \mathrm{~nm}$ band was recorded at different gate-widths and the phosphorescence time-decay was quantified. In Fig. 8B the integrated emission plotted vs. the gatewidth time $\left(w_{t}\right)$ is shown. Assuming a single exponential decay, fitting to a function:

$$
y\left(w_{t}\right)=A^{*}\left(1-\exp \left(w / \tau_{p h}\right)\right.
$$

gave the phosphorescence life-time $\tau_{\mathrm{ph}}=2.3 \mathrm{~ms}$, as shown in Fig. 8:B. 
A)

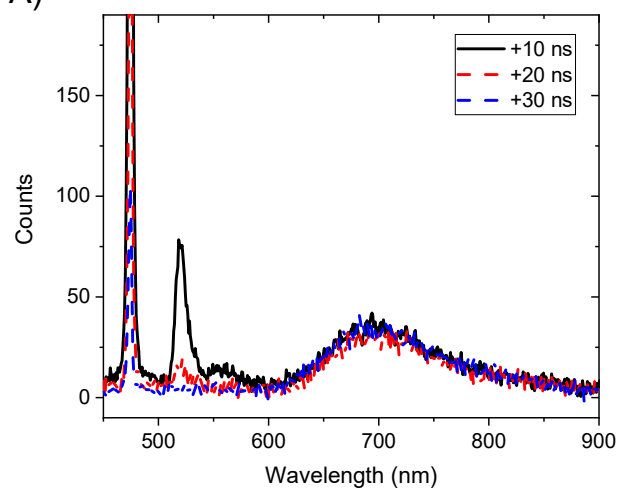

B)

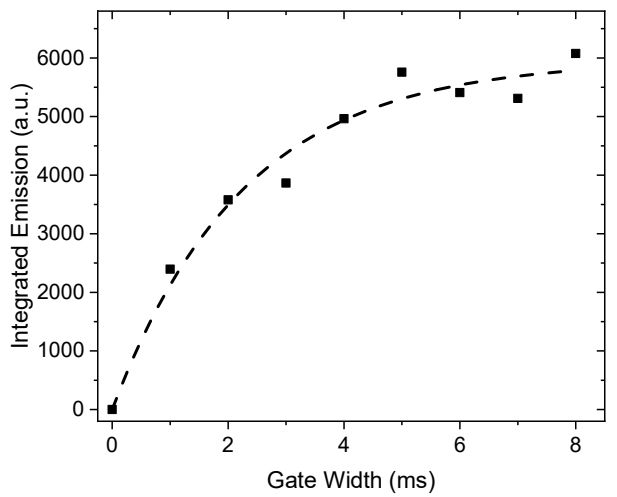

Figure 8: A) Emission spectra of BAD-3 at $77 \mathrm{~K}$ and recorded with different gate-delays after the laser pulse as indicated in the inset (the gate width was 5 $\mathrm{ms}$ ). B) Plot of the integrated emission above $600 \mathrm{~nm}$ and at different gatewidths. The gate-delay was approximately $80 \mathrm{~ns}$ after the laser excitation. The solid line is a fit yielding a phosphorescence decay time of $2.3 \mathrm{~ms}$.

\section{Singlet oxygen yield from transient luminescence}

Time-resolved experiments were carried out using freshly prepared samples due to the possible photo-decomposition of the BADs. The time profile of singlet oxygen emission of BADs 3 was measured and compared to EryB in $\mathrm{ACN}^{22}$ using laser excitation at $457 \mathrm{~nm}$, at which the samples had the same absorption (OD = 0.068) at this wavelength (Fig. 9)

Upon excitation with a ns OPO laser (40-50 $\mathrm{mJ} / \mathrm{pulse})$, the emitted luminescence at $1275 \mathrm{~nm}$ was recorded, excluding spurious signals with bandpass filters. The emission profiles of generated singlet oxygen were fitted to a double exponential as outlined by Snyder et al. ${ }^{23}$

$$
S(t)=A *\left(-\exp \left(-t / \tau_{r}\right)+\exp \left(-t / \tau_{d}\right)\right),(\text { Eq. } 2),
$$

where $A$ is the maximum amplitude of the signal $S(t), \tau_{r}$ and $\tau_{d}$ are the rise- and the decay constants of the signal, respectively. The rising part of the signal is due the quenching of the triplet precursor of EryB (or BAD-3) and the decay tail is due to the return of singlet oxygen to the ground state..$^{23,24}$

The dashed curves are simulations calculated from fitting the experimental decays following a step-by-step approach. The singlet oxygen decay was determined to $85.5 \mu \mathrm{s}$ by fitting the tail above $40 \mu \mathrm{s}$. This is in accordance with the value of $80.9 \mu \mathrm{s}$ (s. d. $2 \%$ ) recorded at $25^{\circ} \mathrm{C}$ by Bregnhøy et. al., ${ }^{25}$ taking into account the difficulty to accurately fit the long tail of the mixed transient of

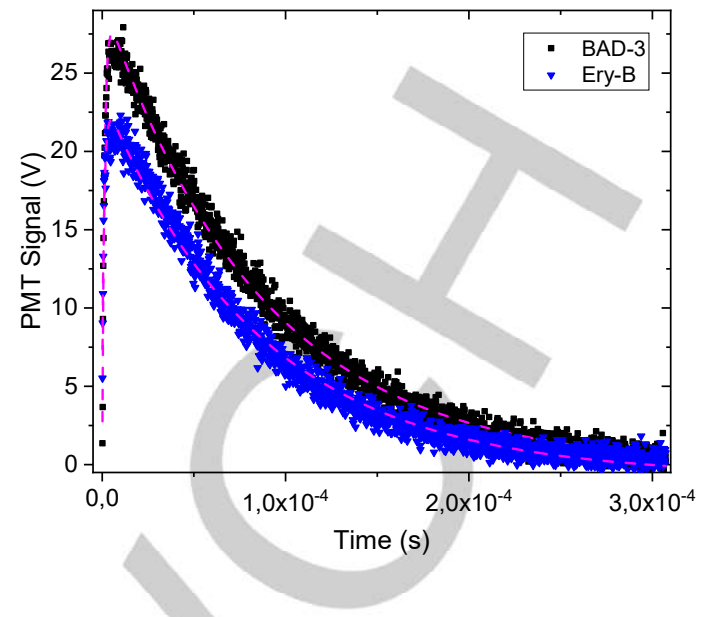

Figure 9: Time profile of singlet oxygen emission of EryB and BAD-3 with model fit recorded at $1275 \mathrm{~nm}$ after laser excitation at $457 \mathrm{~nm}$. The dashed curves show simulations using a rise time of 1.26 and 1.18 for BAD-3 and EryB, respectively. The singlet oxygen decay time was fitted to $85.5 \mu$ s for both cases.

eq. 2. By fixing this value, the amplitude and the rise-time were fitted. Hence, from the amplitude value the singlet oxygen quantum efficiency of BAD-3 in ACN was estimated to be $22 \%$ higher than for Ery-B giving a singlet oxygen yield of approximately $70-80 \%$ for BAD-3 using literature reference values. ${ }^{26}$ Similar results were obtained for BAD-3 using other solvents, such as $\mathrm{MeOH}$ and $\mathrm{EtOH}$; however, very weak singlet oxygen transient signals were observed for the BADs in water or deuterium oxide $\left(\mathrm{D}_{2} \mathrm{O}\right)$ (Fig. SI12). Using Fig. SI12, the apparent decay time of the singlet oxygen quenching for BAD-3 at $514 \mathrm{~nm}$ and were calculated as 16 and $17 \mu \mathrm{s}$ in $\mathrm{EtOH} ; 10.5$ and $10.7 \mu \mathrm{s}$ in $\mathrm{MeOH}$, for EryB and BAD-3, respectively. For EryB in $\mathrm{D}_{2} \mathrm{O}$ the truncated transient fitted values were found to be approximately $72 \mu$ s. The singlet oxygen life-time values are in agreement with values reported in the literature. ${ }^{25,27}$ The results for BAD-1 and BAD-2 are also shown in the SI (Fig. SI13).

The absence of oxygen prevents singlet oxygen production, further proving that the BADs produce singlet oxygen in certain solvents. Both singlet oxygen lifetime and total yield are dependent on the solvent. In general, nonpolar solvents, particularly those having halogenated molecules, dissolve $>\mathrm{mM}$ concentrations of oxygen, whereas water can dissolve only a few $\mu \mathrm{M}$ in ambient solvents. ${ }^{28}$ Moreover, non-protic and nonpolar solvents also show longer decay times and singlet oxygen is difficult to detect in water, as the decay is in the 3-4 $\mu$ s range, in addition to low solubility. ${ }^{24,25,27}$ The BADs examined did not show any appreciable singlet oxygen yield in water or $\mathrm{D}_{2} \mathrm{O}$ but rich yields were produced in $\mathrm{ACN}, \mathrm{MeOH}$, and $\mathrm{EtOH}$.

\section{Transient absorption spectra of the triplet states}

To generate a triplet absorption spectrum a laser pulse (pump) was used to excite the sample and the transient absorption (TA) spectrum was measured using a short-lived flash (probe) at some delay after the pump. ${ }^{10,11,29}$ The samples were deoxygenized using argon for at least 8 minutes. The excitation wavelength used was $514 \mathrm{~nm}$ and the spectra were recorded at a concentration of $10 \mu \mathrm{M}$ in $\mathrm{EtOH}, \mathrm{MeOH}$, and $\mathrm{D}_{2} \mathrm{O}$ are shown in (Fig. 10 and Fig. $\mathrm{SI} 14)$. As seen in Figure $\mathrm{SI} 14$ the triplet state is quenched in $\mathrm{D}_{2} \mathrm{O}$ (and water, not shown) but forms readily in both $\mathrm{EtOH}$ and $\mathrm{MeOH}$, 
corroborating the singlet oxygen yields. Note particularly that BAD-1 yielded a weak transient triplet absorption spectrum (Fig. SI14:A) along with a weak transient singlet oxygen luminescence (Fig. SI13:C), in $\mathrm{D}_{2} \mathrm{O}$.

A close-up of the TA spectrum of BAD-3 in EtOH at zero delay after the pump is shown in Figure SI15, together with the ground state absorption (GSA) spectrum recorded using the same sample and array detection system but a continuous white light source. The transient absorption spectrum is defined by Eq. 3 to account for the depletion of the ground state:

$$
\Delta(\lambda, t) \equiv A_{p}-A_{p}^{l}(t)=\Delta c *\left(\varepsilon_{T}-\varepsilon_{g}\right), \quad(\text { Eq. 3) }
$$

Here, $\lambda$ is the wavelength and $t$, is the delay between the pump and the probe flash. $\boldsymbol{A}_{p}$ and $\boldsymbol{A}_{\boldsymbol{p}}^{l}(\boldsymbol{t})$ are the absorption spectra using only the probe and both pump and probe, respectively. $\Delta c$ is the concentration change in the ground state molecules caused by the pump, and $\varepsilon_{g}$ and $\varepsilon_{T}$ are the extinction coefficients of the ground state and the photo-product, respectively. $\Delta c$ can be found by adding a certain fraction of the ordinary absorption spectrum $A_{p}$, such as given by

$$
\left.f=\frac{\Delta c}{c}=0.53, \quad \text { (Eq. } 4\right)
$$

in our case. This is added to $\Delta(\lambda, t)$ to compensate for the ground state depletion (GSD), as shown as the blue line in Fig. 14 and 15 . The irregularity in the TA and absorption at $514 \mathrm{~nm}$ is due to the laser excitation (apart from a difference in intensity, laser excitation at both $355 \mathrm{~nm}$ or $514 \mathrm{~nm}$ gave the same TA spectrum). The $550-700 \mathrm{~nm}$ part is attributed to triplet-triplet (T-T) absorption within the BODIPY unit of the dyad.

The $300-400 \mathrm{~nm}$ region of the TA spectrum bears a remarkable similarity to the ground state absorption spectrum of the same wavelength region

$$
a=f \cdot A_{p},
$$

which is due to the anthracene part of the dyad.

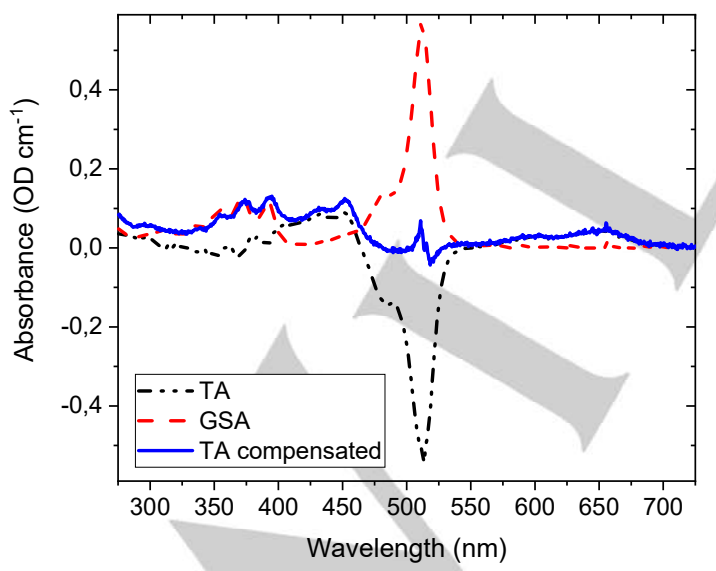

Figure 10: The TA spectrum of BAD-3 along with the GSA spectrum and compensated TA spectrum in EtOH. Red dash: Downscaled GSA spectrum of BAD-3 to match its GSD in the TA spectrum in the BAD-3 region of maximum absorption. Black dash-dot: TA at zero delay between laser and probe pulse. Blue: Sum of TA and $53 \%$ of GSA.

Elimination of the GSD of the BODIPY unit $(470-530 \mathrm{~nm})$ in the dyad spectrum overcompensate for the GSD of the anthracene unit of the dyad. To erase the GSA characteristics in that region, it was found that a smaller fraction had to be added:

$$
f_{2}=\frac{\Delta c_{2}}{c}=0.32 \quad \text { (Eq. 6). }
$$

Furthermore, it was shifted to a longer wavelength by $1.5 \mathrm{~nm}$. The remaining peaks at 434 and $452 \mathrm{~nm}$, sitting on top of a broader band due to the BODIPY unit, are the characteristic T-T absorption bands of anthracene although the bands here are slightly red-shifted compared to results from early work that used benzene and paraffine as the solvent. ${ }^{30,31}$

Conclusively, the laser excitation causes approximately $50 \%$ of BAD-3 to enter the lowest BODIPY triplet and $30 \%$ to anthracene triplets; in total $80 \%$.

\section{Kinetics of transient absorption}

Finally, we studied the kinetics of the transient absorption by recording the time changes of in the transient absorption spectra in the microsecond regime, at selected wavelengths; $\Lambda_{1}=650 \mathrm{~nm}$, $\Lambda_{2}=450 \mathrm{~nm}, \Lambda_{3}=430 \mathrm{~nm}$, and $\Lambda_{4}=520 \mathrm{~nm}$. The absorbance changes at $\Lambda_{1}$ is used to monitor the change in concentration of the BODIPY triplets, $A\left(\Lambda_{2}\right)$ and $A\left(\Lambda_{3}\right)$ will monitor mostly anthracene unit triplet, while $A\left(\Lambda_{4}\right)$ will monitor GSD of the BODIPY unit (Fig. 11)

As the observed kinetics did not fit to mono-exponential decays a mixed first and second order decay model as outlined by Heppel (please see SI for details). ${ }^{32}$

$$
C(t)=\frac{k_{1} \cdot C_{0} \cdot \exp \left(-k_{1} \cdot t\right)}{k_{1}+k_{2} \cdot C_{0} \cdot\left(1-\exp \left(-k_{1} \cdot t\right)\right)}, \quad(\text { Eq. 7) }
$$

where $C_{0}=C(t=0)$ is the initial concentration of the reactant.

The observed kinetic traces are well described by this equation for mixed decay. The rate constants and the initial concentration were found by fitting the observed traces to Eq. 7. Examples of the fits are shown in Fig. 11. The fitted decay rates give some clues how to interpret the triplet state reactivity/stability.

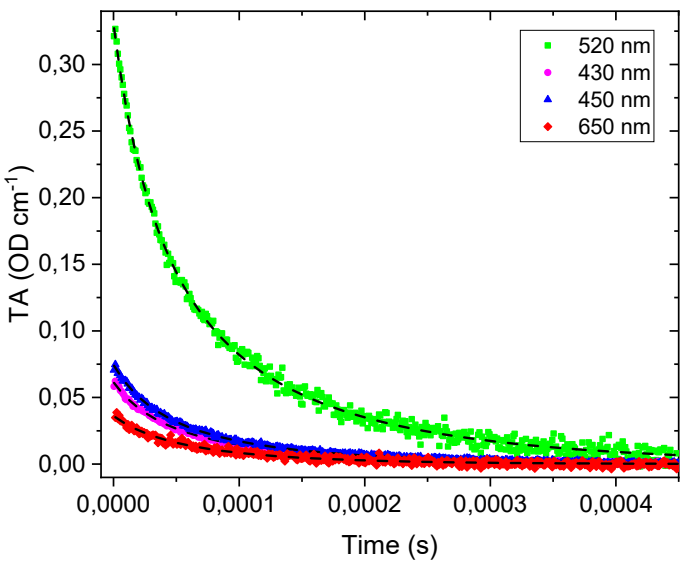

Figure 11: TA at selected wavelengths after the laser pulse with continuous argon bubbling of the solution. N.b.: the signal at $520 \mathrm{~nm}$ has been inverted to show positive values. The black dashed lines are fits of Eq. 7 with the parameters summarized in Table SI3.

Firstly, bear in mind these are measured under argon, so no oxygen reaction is at hand as a decay route. Both the BODIPY $(650 \mathrm{~nm})$ and the anthracene $(430 ; 450 \mathrm{~nm})$ spectra decays (via 
k1) slightly faster than the GSD recovery rate according to the decay fitting analysis. This is reasonable, as the concentration of the transient species probably are different, and the recombination probably occur so that the anthracene triplet goes with another anthracene triplet, etc., making the total depletion recovery slower. Taking the singlet oxygen and triplet characterization results together, a plausible explanation for both the low singlet oxygen yield and no appearance of a triplet state in water or $\mathrm{D}_{2} \mathrm{O}$ might be that the charge transfer state shifts to lower energy due to the increased polarity.

\section{Conclusions}

To conclude, we undertook an investigation into the structural, photobiological, and photophysical properties of BAD-3 to better understand to assess its potential as a photodynamic therapy agent. We elucidated the crystal structure and can see that the compound has a hydrophobic end and a hydrophilic end. BAD-3 gave a strong therapeutic response against the AY27 cell line. Additionally, cytotoxicity was observed in the F98 cell line for BAD-3, indicating its potential as a versatile photodynamic therapy agent. We used flow cytometry to show that both necrosis and apoptosis are responsible for the observed therapeutic effect. Fluorescence microscopy demonstrated that the BAD-3 crossed the cell membrane and localized $(22 \%)$ in the lysosomes.

Regarding the photophysical characteristics, we used transient absorption to conclude that laser excitation causes approximately $50 \%$ of BAD-3 to enter the lowest BODIPY triplet and $30 \%$ to enter anthracene unit triplets for a total triplet state formation of $80 \%$. This translated to a singlet oxygen quantum yield of approximately $70-80 \%$, in agreement with estimates of the yield from direct measurements of the transient luminescence of singlet oxygen at $1275 \mathrm{~nm}$. The yield in water and $\mathrm{D}_{2} \mathrm{O}$ was minimal and only detected for BAD-1. This was further corroborated in the triplet excited state measurements. Finally, the decay of the triplet generated from BAD-3 was shown to follow a mixed first and second order decay profile. The current study confirmed that BAD-3 is the most suitable BODIPY-anthracene dyad for medical applications and has given us a better understanding of the characteristics of BAD-3 with the view of translating this photosensitizer to an in vivo model.

\section{Experimental Section}

Experimental Details: BADs 1-3 were synthesized and characterized in accordance with our previous reports. ${ }^{13 a, 14}$

$X$-ray Crystallography. Crystals were grown following the protocol developed by Hope, which involved dissolving the compounds in $\mathrm{H}_{2} \mathrm{O}$ and layering with a second solvent (hexane) for liquid diffusion. ${ }^{33}$ The singlecrystal X-ray diffraction data for this compound was collected on a Bruker APEX 2 DUO CCD diffractometer using graphite-monochromated $\mathrm{Cu} K_{a}$ $(\lambda=1.54178 \AA)$ radiation. The crystal was mounted on a MiTeGen MicroMount and collected at 100 (2) K using an Oxford Cryosystems Cobra low-temperature device. The data was collected using omega and phi scans and was corrected for Lorentz and polarization effects using the APEX software suite. ${ }^{34-36}$ Using Olex2, the structure was solved with the $\mathrm{XT}$ structure solution program, using the intrinsic phasing solution method and refined against $\left|F_{2}\right|$ with $X L$ using least square minimization. ${ }^{37,38}$ The hydrogen atoms were generally placed in geometrically calculated positions and refined using a riding model. Details of the data refinements can be found in Table S1. All images were prepared using Olex2. ${ }^{37}$ The carbon and nitrogen bound hydrogen atoms were placed in their expected calculated positions and refined as riding model: $\mathrm{C}-\mathrm{H}=0.95-0.98 \AA$, with $1.2 U_{\text {eq }}(\mathrm{C})$ for all $\mathrm{H}$ atoms. Further refinement of the sulfonate moiety proved to be unsuccessful and modeling a proper acceptor unit for H7B (water molecule) hampered the overall data quality. CCDC 1988951 contain the supplementary crystallographic data for this paper. These data can be obtained free of charge from The Cambridge Crystallographic Data Centre via www.ccdc.cam.ac.uk/structures.

Cell cultivation: The AY27 cell line originates from a transitional cell carcinoma in a rat bladder and was supplied by Professor Steven $\mathrm{H}$ Selman from the Medical College of Ohio, Toledo, USA in 2004. The cells were grown in sterile $75 \mathrm{~cm}^{2}$ culture flasks, in RPMI-1640 growth medium (Catalogue No. R0883 Sigma Aldrich). The medium was supplemented with $10 \%$ fetal bovine serum (Catalogue No. F-7524), 0.33\% L-glutamine (200 mM, Catalogue No. G-7513), and 1\% penicillin/ streptomycin (10 $\mathrm{U} / \mathrm{mL} / 10 \mathrm{~g} / \mathrm{mL}$. Catalogue No. P-0781). All of the supplements were obtained from Sigma Aldrich. The cells were kept in an incubator at $37^{\circ} \mathrm{C}$ in a humidified atmosphere containing $5 \% \mathrm{CO}_{2}$. Twice a week, after reaching $80-90 \%$ confluence, the cell cultures were split. The medium was removed from the flask and the cells were washed once in phosphatebuffered saline (PBS) to discard dead cells and traces of old medium. The cells were detached from the flask by adding typsin/ethylenediaminetetraacetic acid solution (3 $\mathrm{mL}, 0.25 \% / 0.02 \%$, Catalogue No. T-4049, Sigma Aldrich) and incubated at $37^{\circ} \mathrm{C}$ for $5 \mathrm{~min}$. The trypsinated cells were then transferred to a test tube and centrifuged at 1500 RPM for $5 \mathrm{~min}$. A cell suspension with a final concentration of $10^{6}$ cells $/ \mathrm{mL}$ was formulated. From this suspension, two new flasks were sown and medium was added for a total of $15 \mathrm{~mL}$ per flask. In addition to the sub-culturing, the cells underwent medium change and washing in PBS once a week.

Photodynamic therapy: The cells were trypsinated, centrifuged, and counted as previously described. They were subsequently divided into 16 containers, each with an equal number of cells. For some experiments, wells situated on an objective glass were used. The walls of the wells could be removed after the treatment, allowing for immediate analysis by microscopy without needing to detach the cells from the glass. Each well was sown with $0.1 \times 10^{6}$ cells in $1 \mathrm{~mL}$ of medium. In the other experiments, Petri dishes $(6 \mathrm{~cm} \times 1.5 \mathrm{~cm})$ were used, each sown with $0.5 \times 10^{6}$ cells in 3 $\mathrm{mL}$ of growth medium. The cells were carefully resuspended continuously throughout the seeding process. After seeding, the cells were incubated overnight $(24 \mathrm{~h})$ at $37^{\circ} \mathrm{C}$. The next day, the medium in the dishes was removed, and cells were washed once with PBS. BAD-3 was then mixed with the new growth medium $(10 \mu \mathrm{M})$. The medium containing the photosensitizer was distributed into the dishes marked for treatment. The control dishes and dishes only receiving light were refilled with the same amount of normal growth medium. From this point on, all of the cell dishes were maintained under dark conditions using aluminum foil when not undergoing illumination. The cells were again incubated for $24 \mathrm{~h}$. Prior to illumination, the medium containing BAD-3 was removed from the dishes and the cells were washed twice with PBS to remove any extracellular traces of the photosensitizer. Then, a small amount of PBS was added to cover the cells during the illumination process. Immediately after the removal of the BAD-3 containing medium and the addition of PBS, the cells were placed on the LumiSource $®$ lamp $\left(435 \mathrm{~nm}, 12.9 \mathrm{~mW} / \mathrm{cm}^{2}\right)$ for the specified time. When removed from the lamp, the dishes were quickly covered to avoid any excess illumination. The PBS was removed from the dishes and the cells were resupplied with growth medium. Before the MTT assay, the cells were incubated overnight for $20 \mathrm{~h}$.

Mitochondrial dehydrogenase assay MTT assay The MTT cell proliferation assay was performed $24 \mathrm{~h}$ after irradiation. ${ }^{16}$ The culture medium was removed and the cells were incubated with MTT solution $(0.5$ $\mathrm{mg} / \mathrm{mL}$, Sigma-Aldrich, St. Louis, MO) for $1 \mathrm{~h}$ at $37^{\circ} \mathrm{C}$. The MTT medium was replaced by isopropanol $(2 \mathrm{~mL})$ before being placed on a plate shaker for $30 \mathrm{~min}$ at $80 \mathrm{RPM}$. The cell suspensions were centrifuged for $5 \mathrm{~min}$ at 1500 RPM as described in the reversed protocol by Gederaas et al. The 
supernatants were diluted with isopropanol before the absorbance at 595 $\mathrm{nm}$ (using a Shimadzu UV-1700 spectrophotometer, China) was measured. The data was processed and compared to that of the untreated cells. ${ }^{39}$

Flow cytometry. The cells were analyzed using a Beckman Coulter Gallios Flow Cytometer (4 laser, 10 color system). Before analysis, the cells were washed with PBS and detached from the Petri dishes using trypsin $(1 \mathrm{~mL})$. The contents of each dish were then moved into separate tubes together with growth medium $(3 \mathrm{~mL})$. From each tube, a small amount $(10 \mu \mathrm{L})$ of the cell suspension was taken and added to a disposable cell counting chamber to be used in a Countess ${ }^{\mathrm{TM}}$ automated cell counter (Cat. No. C10227). After the cell population of each tube was calculated, the tubes were centrifuged for $5 \mathrm{~min}$ at $1500 \mathrm{RPM}$ and the supernatant was discarded. The resulting cell pellet was resuspended in cold PBS.

Apoptosis/necrosis analysis. An Alexa Fluor® 488 annexin V/Dead Cell Apoptosis Kit (Cat. No. V13241, Invitrogen), containing annexin V, PI, and annexin-binding buffer solution was used for the apoptosis/necrosis analysis. To prepare the samples, the PBS was removed from the tubes by centrifugation for $5 \mathrm{~min}$ at $1500 \mathrm{RPM}$. The cell pellet was resuspended at a concentration of $1 \times 10^{6} \mathrm{cells} / \mathrm{mL}$ in the annexin-binding buffer solution. $100 \mu \mathrm{L}$ or $1 \times 10^{5}$ cells were then transferred to the flow cytometer tubes. $\mathrm{PI}(1 \mu \mathrm{L}, 100 \mu \mathrm{g} / \mathrm{mL})$ and Alexa Fluor 848 annexin $\mathrm{V}(5 \mu \mathrm{L})$ were added to each tube and the tubes were incubated at room temperature for $15 \mathrm{~min}$ After incubation, annexin-binding buffer solution $(400 \mu \mathrm{L})$ was mixed into the samples and the samples were immediately analyzed in the flow cytometer. The fluorochromes were excited at $488 \mathrm{~nm}$ and fluorescence was measured at $530 \mathrm{~nm}$ and $575 \mathrm{~nm}$.

Localization studies. AY27 cells were seeded (30 000 cells per dish) in 8-well chambered coverslips $\left(A_{\text {well }}=1 \mathrm{~cm}^{2}\right)(\mu$-Slide 8 Well, ibidi $\mathrm{GmbH}$, Gräfelfing, Germany), and incubated $\left(24 \mathrm{~h}, 37^{\circ} \mathrm{C}\right)$ with BAD-3 $(10 \mu \mathrm{M})$. After incubation, cells were treated with $120 \mathrm{~s}$ of illumination with blue light (LumiSource Lamp, $435 \mathrm{~nm}$ ). Then, they were immediately incubated again with either Draq5 $\left(20 \mu \mathrm{M}, 300 \mu \mathrm{L}, 3 \mathrm{~min}, 37^{\circ} \mathrm{C}, 5 \% \mathrm{CO}_{2}\right)$ or LysoTracker Blue $\left(75 \mathrm{nM}, 300 \mu \mathrm{L}, 1 \mathrm{~h}, 37^{\circ} \mathrm{C}, 5 \% \mathrm{CO}_{2}\right)$ and CellMask Red (1 $\mathrm{nM}, 10 \mathrm{~min}, 37^{\circ} \mathrm{C}, 5 \% \mathrm{CO}_{2}$ ) and imaged. The cells were imaged employing a confocal laser scanning microscope (Leica TCS SP8 MP, Leica Microsystems, Germany), using a plan apochromatic HCX IRAPO $25 \times$ water immersion objective with a numerical aperture of 0.95. BAD-3 was excited at $513 \mathrm{~nm}$ with a WLL laser. Draq5 and CellMask Red were excited using a WLL laser at $646 \mathrm{~nm}$ and $650 \mathrm{~nm}$, respectively, while LysoTracker Blue was excited by a $405 \mathrm{~nm}$ pulsed laser. The excitation period during the measurement of the images was approximately $5 \mathrm{~s}$. All of the emissions were detected through a 1 Airy Unit pinhole. The laser power, detector gain, and offset were chosen to minimize autofluorescence in the control samples where no photosensitizer was added. For further processing, 1024 by 1024 -pixel images with an 8 bit dynamic range were recorded. The assessment of the colocalization in the aforementioned experiments was based on algorithm and software analysis developed in-house using the Python 3 programming language. Briefly, the brightness and dye concentration of each image can differ, so a normalized colocalization parameter was defined, as shown in equation (Eq. 8):

$$
\mathrm{C}_{f}(\%)=100 \times\left(\mathrm{N}_{\mathrm{cp}} /\left(\left(\mathrm{N}_{1}+\mathrm{N}_{2}\right)-\mathrm{N}_{\mathrm{cp}}\right), \quad\right. \text { (Eq. 8) }
$$

where $\mathrm{N}_{\mathrm{cp}}$ is the number of pixels in the colocalized image, and N1 and N2 are the number of pixels over the threshold for the individual images to be compared. ${ }^{16}$ This formula gives 1 at the limit when all pixels are colocalized and goes to zero when no pixels are colocalized, as might be expected. This allows us to make a statistical assessment of the colocalization in different cells and compare different cell cultures. Regions of low signal (no visible cells or other features) were used to estimate the noise level of each wavelength channel, and this was used to set the thresholds.
Basic optical spectroscopy. Steady state absorption spectra were recorded using a Shimadzu UV-1601PC spectrophotometer Measurements were performed with $10 \mathrm{~mm}$ quartz cuvettes (Hellma Precision) with a teflon cap allowing for gas-purging using syringe needles. Steady state photoluminescence measurements were carried out employing a PTI Quantamaster 8075-22 (Horiba Scientific) equipped with Double Mono 300 spectrometer chambers for both excitation and emission. A Hamamatsu R928 PMT was used for detection in the range 185 - 950 $\mathrm{nm}$. A OB-75X (75W Xenon arc lamp) was used as the light source. For singlet oxygen luminescence a detection port of the spectrometer was directed to a $1427 \mathrm{C}-\mathrm{AH}$ detector coupler together with a liquid nitrogen cold Indium-Gallium-Arsenide solid state detector (Horiba Scientific: DSSIGA020). Data acquisition and basic data-handling of steady state luminescence data were carried out with the Felix Data Analysis software and further processed and presented using Origin Pro. Time-resolved fluorescence decays were recorded using an IBH time-correlated single photon counting (TCSPC) spectrometer system with $1 \mathrm{~nm}$ resolved emission monochromator (5000 M, Glaskow, UK). The system was equipped with a TBX-04D picosecond photon detection module and the sample was excited using an IBH LED operating at $469 \mathrm{~nm}$. The measured decay-trace was analyzed using deconvolution fitting with the IBH Data Station v 2.1 software. For more details on the procedures, see Glimsdal et al. ${ }^{40}$

Microscopy. The medium was removed and each well was washed with PBS three times. The cells were then fixed by the addition of $\mathrm{MeOH}(0.5$ $\mathrm{mL},-20^{\circ} \mathrm{C}$ ) and incubated in a freezer $\left(10 \mathrm{~min},-20^{\circ} \mathrm{C}\right)$. Next, the $\mathrm{MeOH}$ was removed and the cells were washed with PBS. The cells were pictured in brightfield mode using a Nikon Eclipse TS100 microscope and underwent fluorescence microscopy in a Leica TCS SP8 MP confocal laser scanning microscope. When using the brightfield microscope, the cells were viewed in PBS but for the confocal microscopy, the cells were visualized in one drop of VectaShield (Cat. No. H-1000, Vector Laboratories) following the removal of the PBS. This was done to minimize photobleaching. The samples were excited at $490 \mathrm{~nm}$ and fluorescence was measured in the range of $550 \mathrm{~nm}$ to $650 \mathrm{~nm}$

Laser flash photolysis measurements. The flash photolysis measurements were performed using a laser flash photolysis spectrophotometer from Applied Photophysics (LKS.80, Leatherhead United Kingdom) and a Nd:YAG Laser System (EKSPLA NT342B-SH-10WW, Vilnius Lithuania). The differential absorption spectra with microsecond time resolution were acquired using an ungated 2048channel spectrograph (BWTek model BRC642E) covering the 190-1100 $\mathrm{nm}$ spectral range. The sensor array is a back-thinned CCD, enclosed within the unit containing the dispersing device. The probe beam, traveling at a right angle to the laser beam, was derived from a compact xenon flash lamp (Hamamatsu L9456-01) that delivers an intense flash of about $1 \mu \mathrm{s}$ in duration (with FWHM of about $500 \mathrm{~ns}$ ). The transmitted part of the probe beam was received by an optical fiber connected to the spectrograph. Let $S_{k}^{ \pm \pm}$denote the output of the $k$ th channel, where the first (second) superscript indicates whether a shutter blocking the probe (pump) beam is open $(+)$ or closed $(-)$. Laser-induced changes in the absorbance of the sample at each channel were calculated using the following equation (Eq. 9):

$$
\Delta A_{k}=\log \left[\left(S_{k}^{+-}-S_{k^{--}}\right) /\left(S_{k}^{++}-S_{k^{-+}}\right)\right] \text {(Eq. 9) }
$$

Unless otherwise mentioned, the absorption spectra were measured at a $1 \mu$ s delay between the pump (laser) and probe (flashlamp). The BWTek software allows for the detection of three spectra, so $\mathrm{S}^{+-}, \mathrm{S}^{++}$, and $\mathrm{S}^{-+}$were measured. The $\mathrm{S}^{-+}$spectrum (no probe, laser pulse) contains fluorescence from the sample, which is restricted to a limited wavelength range. The background noise of BWTek is wavelength-independent (the $\mathrm{S}^{-}$ spectrum; no probe, no laser) and is therefore taken to be the diode readings outside the fluorescence range. The spectra were imported to Excel where $\Delta \mathrm{A}_{\mathrm{k}}$ was calculated. A single-wavelength kinetic spectrometer (Applied Photophysics model LSK-80) was used for recording $\Delta \mathrm{A}_{(\lambda, t) \text {, the }}$ time-dependent change in the laser-induced absorbance at a monitoring 
wavelength $\lambda$. The time resolution of this instrument is limited by the duration of the laser pulse (6 ns).

\section{Transient Singlet Oxygen Luminescence Measurements}

The singlet oxygen luminescence lifetime and yield were measured from the transient luminescence of a solution containing the dye in a standard $90^{\circ}$ configuration. A tunable OPO laser, NT342A-SH-10-WW (Ekspla, Lithuania) was used for excitation. Typically, pulses of energy $40-50 \mathrm{~mJ}$ were used. For transient recording, a PMT (R5509, Hamamatsu) and a bandpass interference filter with maximum transmission at $1272.5 \mathrm{~nm}$ and a long pass filter transmitting above $780 \mathrm{~nm}$ ) were used in conjunction to avoid spurious signals. An Infiniium BDSU Oscilloscope (Keysight, United States) was used to collect and monitor data. Time-gated electronics was used to control the time between the laser excitation and the recording of the luminescence transient. To obtain a reference signal (minimum amount of air/oxygen) the sample cell was bubbled with argon gas for 10 $\min$. For the time-gated measurements of luminescence at $77 \mathrm{~K}$ the same laser was employed as for the singlet oxygen luminescence. A Hamamatsu Photonic Multi-channel analyzer C10029 and a Stanford Research Systems Inc., Model DG 535, 4 channel digital delay pulse generator were used to set the delay and gate-width and record a full spectrum in one laser-flash. Here samples were prepared by freezing the solvent in liquid nitrogen $(77 \mathrm{~K})$ in $4 \mathrm{~mm}$ EPR tubes and then measured placing an EPR liquid nitrogen finger-tip Dewar flask at the position of the normal sample holder (for $1 \times 1 \mathrm{~cm}$ cuvettes) for optical spectroscopy.

\section{Acknowledgements}

This work was supported by grants from Science Foundation Ireland (IVP 13/IA/1894) and the Irish Research Council (GOIPG/2016/1250).

Keywords: BODIPY-anthracene dyad • Photosensitizer • Flow cytometry • Direct singlet oxygen measurement $\cdot$ Transient absorption spectroscopy $\cdot$ X-ray crystallography $\cdot$ Cytotoxicity

[1] a) T. J. Dougherty, C. J. Gomer, B. W. Henderson, G. Jori, D. Kessel, M Korbelik, J. Moan, Q. Peng, J. Natl. Cancer Inst. 1998, 90, 889-905; b) B. W. Henderson, T. J. Dougherty, Photochem. Photobiol. 1992, 55 145-57; c) A. Wiehe, J. M. O'Brien, M. O. Senge, Photochem. Photobiol. Sci. 2019, 18, 2565-2612.

[2] D. M. Arias-Rotondoa, J. K. McCusker, Chem. Soc. Rev. 2016, 45 5803-5820.

[3] R. C. Evans, P. Douglas, C. J. Winscom, Coord. Chem. Rev. 2006, 250, 2093-2126.

[4] a) J. Zhou, Q. Liu, W. Feng, Y. Sun, F. Li, Chem. Rev. 2015, 115, 395465; b) N. Kiseleva, M. A. Filatov, M. Oldenburg, D. Busko, M. Jakoby, I. A. Howard, B. S. Richards, M. O. Senge, S. M. Borisov, A. Turshatov, Chem. Commun. 2018, 54, 1607-1610.

[5] A. Kamkaew, S. Hui Lim, H. B. Lee, L. V. Kiew, L. Y. Chung, K. Burgess, Chem. Soc. Rev. 2013, 42, 77-88.

[6] S. Banfi, E. Caruso, S. Zaza, M. Mancini, M. B. Gariboldi, E. Monti, J. Photochem. Photobiol. B: Biol. 2012, 114, 52-60.

[7] a) M. R. Wasielewski, Chem. Rev. 1992, 92, 435-461; b) S. Callaghan, M. O. Senge, Photochem. Photobiol. Sci. 2018, 17, 1490-1514; M. A Filatov, Org. Biomol. Chem. 2020, 18, 10-27; D. J. Gibbons, A. Farawar P. Mazzella, S. Leroy-Lhez, R. M. Williams, Photochem. Photobiol. Sci. 2020, 19, 136-158.

[8] W. Pang, X.-F. Zhang, J. Zhou, C. Yu, E. Hao, L. Jiao, Chem. Commun. 2012, 48, 5437-5439.

[9] W. Wu, J. Zhao, J. Sun, S. Guo, J. Org. Chem. 2012, 77, 5305-5312.

[10] W. E. Ford, P. V. Karmat, J. Phys. Chem. 1987, 91, 6373-6380.

[11] J. Baffreau, S. Leroy-Lhez, N. V. Ahn, R. M. Williams, P. Hudhomme, Chem. Eur. J. 2008, 14, 4974-4992.
[12] Z. Wang, A. A. Sukhanov, A. Toffoletti, F. Sadiq, J. Zhao, A. Barbon, V. K. Voronkova, B. Dick, J. Phys. Chem. C 2019, 123, 265-274.

[13] a) M. A. Filatov, S. Karuthedath, P. M. Polestshuk, H. Savoie, K. J. Flanagan, C. Sy, E. Sitte, M. Telitchko, F. Laquai, R. W. Boyle, M. O Senge, J. Am. Chem. Soc. 2017, 139, 6282-6285; b) M. A. Filatov, S Karuthedath, P. M. Polestshuk, S. Callaghan, K. J. Flanagan, M Telitchko, T. Wiesner, F. Laquaic, M. O. Senge, Phys. Chem. Chem Phys. 2018, 20, 8016-8031; c) M. A. Filatov, S. Karuthedath, P. M Polestshuk, S. Callaghan, T. Wiesner, K. J. Flanagan, F. Laquai, M. O. Senge, ChemPhotoChem 2018, 2, 1-11.

[14] S. Callaghan, M. A. Filatov, H. Savoie, R. W. Boyle, M. O. Senge, Photochem. Photobiol. Sci. 2019, 18, 495-504.

[15] A. R. Sekhar, S. K. Sariki, R. V. R. Reddy, A. Bisai, P. K. Sahu, R. S Tomar, J. Sankar, Chem. Comm. 2017, 53, 1096-1099.

[16] a) T. Mosman, J. Immunol. Methods 1983, 65, 55-63; b) J. Carmichael W. G. DeGraff, A. F. Gazdar, J. D. Minna, J. B. Mitchell, Cancer Res. 1987, 47, 936-94.

[17] I. K. Ekroll, O. A. Gederaas, L. Helander, A. Hjelde, T. B. Melø, A. Johnsson, Photochem. Photobiol. Sci. 2011, 10, 1072-1079.

[18] a) J. F. R. Kerr, C. M. Winterford, B. V. Harmon, Cancer 1994, 73, 2013 2026; b) K. M. Debatin, Cancer Immunol. Immunother. 2004, 53, 153159; c) S. Y. Proskuryakov, A. G. Konoplyannikov, V. L. Gabai, Exp. Cell Res. 2003, 283, 1-16.

[19] M. Lindgren, O. A. Gederaas, M. Siksjø, T. A. Hansen, L. Chen, B. Mettra, C.I. Andraud C. Monnereau, Molecules 2020, 25, 1127

[20] K. Tanaka, T. Miura, N. Umezawa, Y. Urano, K. Kikuchi, T. Higuchi, T. Nagano, J. Am. Chem. Soc. 2001, 123, 2530-36.

[21] W. Ni, G. Gurzadyan, L. Ma, P. Hu, C. Kloc, L. Sun, J. Phys. Chem. C 2020, 124, 13894-13901.

[22] (a) M. C. DeRosa, R. J. Crutchley, Coord. Chem. Rev. 2002, 233, $351-$ 371. (b) R. W. Redmond, J. N. Gamlin, Photochem. Photobiol. 1999, 70 391-475.

[23] J. W. Snyder, E. Skovsen, J. D. C. Lambert, L. Poulsen, P. R. Ogilby, Phys. Chem. Chem. Phys. 2006, 8, 4280-4293.

[24] K. Arja, M. Elgland, H. Appelqvist, P. Konradsson, M. Lindgren, K. P. R. Nilsson, ChemistryOpen 2018, 7, 495-503.

[25] M. Bregnhøy, M. Westberg, F. Jensen, P. R. Ogilby, Phys. Chem. Chem Phys. 2016, 18, 22946-22961.

[26] R. W. Redmond, J. N. Gamlin, Photochem. Photobiol. 1999, 70, 391475.

[27] P. R. Ogilby, Chem. Soc. Rev. 2010, 39, 3181-3229.

[28] T. Sato, Y. Hamada, M. Sumikawa, S. Araki, H. Yamamoto, Ind. Eng Chem. Res. 2014, 53, 19331-19337.

[29] E. Glimsdal, I. Dragland, M. Carlsson, B. Eliasson, T. B. Melø, M Lindgren, J. Phys. Chem. A 2009, 113, 3311-3320.

[30] J. Teply, J. Bursik, J. Radioanal. Nucl. Chem. 1986, 101, 369-375.

[31] G Porter, M. W. Windsor, Proc. R. Soc. Lond. A, Math. Phys. Sci. 1958, 245, 238-254.

[32] G. E. Heppell, Photochem. Photobiol. 1965, 4, 7-12.

[33] a) H. Hope, Prog. Inorg. Chem. 1994, 1-19; b) M. O. Senge, Z. Naturforsch. 2000, 55b, 336-344.

[34] Saint, Version 8.37a; Bruker AXS, Inc.: Madison, WI, 2013

[35] SADABS, version 2016/2; Bruker AXS, Inc.: Madison, WI, 2014.

[36] APEX3, Version 2016.9-0; Bruker AXS, Inc.: Madison, WI, 2016.

[37] O. V. Dolomanov, L. J. Bourhis, R. J. Gildea, J. A. K. Howard, H. Puschmann, J. Appl. Crystallogr. 2009, 42, 339-341.

[38] Sheldrick, G., SHELXT - Integrated space-group and crystal-structure determination. Acta Cryst. Sect. A 2015, 71, 3-8.

[39] a) V. Bogoeva, M. Siksjø, K. G Sæterbø, T. B. Melø, A. Bjørkøy, M. Lindgren, O. A. Gederaas, Photodiagnosis. Photodyn. Ther. 2016, 14, 9-17 b) O. A. Gederaas, A. Johnsson, K. Berg, R. Manandhar, C. Shrestha, D. Skåre, I. K. Ekroll, A. Høgset, A. Hjelde, Photochem. Photobiol. Sci. 2017, 16, 1664-1676.

[40] E. Glimsdal, M. Carlsson, T. Kindahl, M. Lindgren, C. Lopes, B. Eliasson, J. Phys. Chem. A 2010, 114, 3431-3442. 


\section{Entry for the Table of Contents}

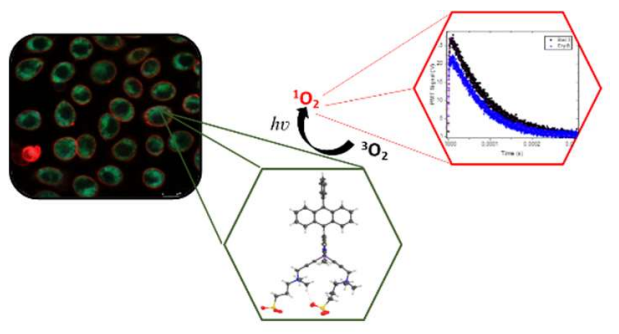

Herein, we report a structural, photobiological, and photophysical investigation of BODIPY-anthracene dyads. We studied cytotoxicity in the AY27 and F98 cell lines and the effect of photodynamic therapy on the AY27 cell line. Additionally, we investigated the excited states of the most promising BODIPY-anthracene dyad using transient absorption spectroscopy and used phosphorescence signals at $1275 \mathrm{~nm}$ to calculate a singlet oxygen quantum yield of $>70 \%$. Finally, the decay of the triplet state was shown to follow a mixed first and second order decay profile. 